Keywords: circulating endothelial cells (CEC); tumour endothelial markers (TEM); CD276; pericytes; endothelial cells; flowytometry; rare events

\title{
Endothelial CD276 (B7-H3) expression is increased in human malignancies and distinguishes between normal and tumour-derived circulating endothelial cells
}

\author{
J Kraan $^{*}{ }^{1}$, P van den Broek ${ }^{1}$, C Verhoef ${ }^{2}$, D J Grunhagen ${ }^{2}$, W Taal ${ }^{3}$, J W Gratama ${ }^{1}$ and S Sleijfer ${ }^{1}$ \\ ${ }^{1}$ Department of Medical Oncology, Erasmus MC Cancer Institute, box 2040, 3000 CA Rotterdam, The Netherlands; ${ }^{2}$ Department \\ of Surgical Oncology, Erasmus MC Cancer Institute, box 2040, 3000 CA Rotterdam, The Netherlands and ${ }^{3}$ Department of \\ Neuro-oncology, Erasmus MC Cancer Institute, box 2040, 3000 CA Rotterdam, The Netherlands
}

Background: Mature circulating endothelial cells (CEC) are surrogate markers of endothelial damage. CEC measured in patients with advanced cancer are thought not only to derive from damaged normal vasculature ( $n-C E C)$, but also from damaged (t-CEC). Therefore, assays that allow the discrimination between these two putative types of CEC are thought to improve the specificity of the enumeration of CEC in cancer.

Methods: Identification of tumour-associated endothelial markers (TEM) by comparing antigen expression on normal vs t-CEC and assess the presence of t-CEC in peripheral blood of cancer patients by incorporating TEM in our novel flow cytometry-based CEC detection assay.

Results: No difference in antigen expression between normal and malignant endothelial cells (ECs) was found for CD54, CD109, CD137, CD141, CD144 and CXCR7. In contrast, overexpression for CD105, CD146, CD276 and CD309 was observed in tumour ECs compared with normal ECs. CD276 was most differentially expressed and chosen as a marker for further investigation. CD276expressing CEC were significantly higher in 15 patients with advanced colorectal cancer (median 9 (range 1-293 cell per $4 \mathrm{ml}$ ); $P<0.005$ ), in 83 patients with a glioblastoma multiforme (median 10 (range 0-804); $P<0.0001$ ) and in 14 patients with advanced breast cancer (median 14 (range 0-390) $P<0.05$ ) as compared with 24 healthy individuals (median 3 (range 0-11)). Of all patients with malignancies, $58 \%$ had CD276 ${ }^{+}$CEC counts above the ULN (8 cell per $\left.4 \mathrm{ml}\right)$.

Conclusions: The present study shows that CD276 can be used to discriminate ECs from malignant tissue from ECs from normal tissue. In addition, CD276+ CEC do occur in higher frequencies in patients with advanced cancer.

Malignant tumours are critically dependent on the formation of new blood vessels for their growth and dissemination (Naumov et al, 2006; Strijbos et al, 2008). Unlike normal tissues, which use sprouting angiogenesis, vasculogenesis and intussusception to form new vessels, tumours also use additional modes of vessel formation. These include the co-optation of pre-existing vessels, the imitation of tumour vasculature (t-CEC) by tumour cells (also known as vascular mimicry), and the differentiation of putative cancer stem-like cells into tumour endothelium. (Carmeliet and Jain, 2011) As a result, t-CEC differs morphologically from normal vasculature (n-CEC), as it features an apparently chaotic mixture of abnormal and hierarchically disorganised vessels with an increased permeability (Nagy et al, 2010).

Next to morphologic differences, in recent years many tumourassociated endothelial markers (TEM) have been identified by comparing gene and protein expression levels between normal and

*Correspondence: J Kraan; E-mail: j.kraan@erasmusmc.nl

Received 17 February 2014; revised 10 April 2014; accepted 25 April 2014; published online 3 June 2014

(c) 2014 Cancer Research UK. All rights reserved 0007-0920/14 
tumour endothelial cells (ECs), demonstrating distinctive gene and protein profiles (Griffioen et al, 1996; Lijnen et al, 2000; Bertolini et al, 2007; Seaman et al, 2007; Nagy et al, 2010; Wurth et al, 2011; Maishi et al, 2012).

Given the central role of vasculature for the growth and development of tumours, various anti-angiogenic agents have been developed and are now under study with the aim to interfere with the vascularisation of tumours. Several clinical trials have demonstrated a benefit in terms of prolonged survival of cancer patients treated with such anti-angiogenic therapies. Further development of this field requires the identification of clinically effective biomarkers that assist the determination of the optimal dose of such agents, the monitoring of their biologic activity, and the selection of patients who are most likely to benefit from this treatment (Bertolini et al, 2007).

Circulating endothelial cells (CEC) are a relative new candidate to monitor vascular effects of anti-angiogenic treatments. CEC are mature ECs, which have been shed from the vascular cell lining as a result of vascular damage. As numerous diseases, including cancer, are associated with vascular damage, enumeration of CEC is being considered a promising tool to monitor disease activity with a potential to assess prognosis and response to treatment (Kraan et al, 2012a). Importantly, CEC measured in patients with advanced cancer are thought not only to derive from damaged n-CEC, but also from damaged $\mathrm{t}$-CEC. Therefore, assays that allow the discrimination between these two putative types of CEC are thought to improve the specificity of the enumeration of CEC in cancer.

Following dissociation, vascular ECs from tumour and normal tissues can be analysed by multiparameter flow cytometry using a combination of exclusion and inclusion markers (Griffioen et al, 1996; Zimmerlin et al, 2010). The aim of the current study is to identify TEM, in order to enable the distinction between t-CEC and $\mathrm{n}$-CEC and to assess the possible detection of t-CEC in peripheral blood (PB) of cancer patients by incorporating TEM enumeration in our novel flow cytometry-based CEC detection assay (Kraan et al, 2012b).

\section{MATERIALS AND METHODS}

Blood and tissue collection. Tumour and macroscopically normal tissues were obtained from patients $(n=17)$ undergoing standard surgical procedures for liver metastasis resection of metastatic colorectal cancer (CRC; $n=11)$ or for resection of a retroperitoneal liposarcoma $(n=6)$. Peripheral blood was collected using EDTAcontaining or CellSave tubes (Veridex, Raritan, NJ, USA) from healthy donors $(n=18)$ or patients with advanced CRC $(n=13)$, advanced breast cancer $(n=9)$ or patients with a glioblastoma multiforme (GBM; $n=73$ ) who relapsed after prior chemoradiation. Samples were stored at room temperature and examined within $8 \mathrm{~h}$ (EDTA-containing tubes) or within $96 \mathrm{~h}$ (CellSave tubes) after venipuncture. All patients provided written informed consent and the study protocols were approved by the local research and ethics committee (protocols METC: 2011-260, 2006248, 2009-405 and P05.182).

Isolation of ECs from tissues. For endothelial cell isolation the resected specimens containing normal or malignant tissue were dissociated using a standardised, semi-automated protocol based on a combination of mechanical tissue disruption and collagenase IV digestion, using a gentleMACS dissociator (Miltenyi Biotec, Bergisch Gladbach, Germany). Briefly, tissues were cut in small pieces $(2-4 \mathrm{~mm})$ in a petri dish prior to collection in a dedicated gentleMACS tube, to which $10 \mathrm{ml}$ of RPMI 1640 (Lonza, BioWhittaker, Walkersville, MD, USA) with $1 \%$ L-Glutamin, $1 \%$ Penicillin/Streptomycin, 10\% heat-inactivated FBS (Sigma Aldrich, St Louis, MO, USA), as well as collagenase IV (Sigma Aldrich),
$1 \mathrm{mg} \mathrm{ml}^{-1}$, and DNAse I (Sigma Aldrich), $10 \mu \mathrm{g} \mathrm{ml}^{-1}$, had been added. The tissues were mechanically minced on the gentleMACS after incubation for $30 \mathrm{~min}$ at $37^{\circ} \mathrm{C}$ in a shaking water-bath. This procedure was repeated once. After the second dissociation step at the gentleMACS, the cell suspension was passed through a $70 \mu \mathrm{m}$ Falcon cell strainer (BD Biosciences, San Jose, CA, USA). The cell suspension was then collected in a $50 \mathrm{ml}$ conical tube, and centrifuged at $1000 \mathrm{~g}$ for $5 \mathrm{~min}$. The resulting pellet was washed with $50 \mathrm{ml}$ phosphate buffered saline (PBS) and concentrated at $2 \times 10^{6}$ cells ml ${ }^{-1}$ in PBS for flow cytometry to detect and characterise the tissue-derived ECs.

Flow cytometry of ECs from tissues. Multiparameter flow cytometry was performed on $100 \mu \mathrm{l}$ of cells stained with $10 \mu \mathrm{l}$ of each of the following monoclonal antibodies ( $\mathrm{mAb}$ ): fluorescein isothiocyanate-conjugated CD34 (clone 8G12; BD Biosciences); peridinin chlorophyll protein-conjugated CD45 (clone 2D1; BD Biosciences); allophycocyanin-conjugated CD146 (clone 541-10B2; Miltenyi Biotec), and $10 \mu \mathrm{l}$ of the DNA dye 5-bis[2-(di-methylamino) ethyl]amino-4, 8-dihydroxyanthracene-9,10-dione (DRAQ5; Biostatus, Shepshed, UK) and $5 \mu \mathrm{l}$ of the nuclear stain $4^{\prime}, 6$ diamidino-2-phenylindole (DAPI). Coexpression of ECs was studied using the following phycoerythrin (PE)-labelled $\mathrm{mAb}$ : CD54 (clone LB2), CD109 (clone TEA 2/16), CD137 (clone 4B4-1) (BD Biosciences), CD105 (clone 1G2), CD144 (clone TEA 1/31) (Beckman Coulter, Miami, FL, USA), CD276 (B7-H3, clone 185504), CD309 (clone 89106) (R\&D systems, Minneapolis, MN, USA), CD141 (clone AD5-14H12, Miltenyi Biotec) and CXCR7 (clone 8F11-M16, Biolegend, San Diego, CA, USA). All reagents were diluted in PBS supplemented with $1 \%$ bovine serum albumin (BSA) based on titration experiments (i.e., absence of non-specific staining on negative populations and optimal discriminatory power between negative and positive populations). After $15 \mathrm{~min}$ of incubation in darkness at room temperature, $2 \mathrm{ml}$ of PBS were added, and the suspension was centrifuged for $5 \mathrm{~min}$ at $500 \mathrm{~g}$. After removal of supernatant, the cells were resuspended in $250 \mu$ l of PBS for acquisition on a BD LSR Fortessa flow cytometer equipped with BD FACSDiva software.

CEC enumeration. CEC enumeration and characterisation was performed as described before (Kraan et al, 2012b). The assay is based on absolute CD34 counts after analysis of all CD34-positive events in a total blood volume of $4 \mathrm{ml}$ using a 'live gate' on $\mathrm{CD} 34^{+}$ events to exclude most of the cells that are not of interest from this analysis. Following this acquisition, CEC are defined as $\mathrm{CD} 34^{++}$, $\mathrm{CD}_{4} 5^{\text {neg }}, \mathrm{CD}_{146}{ }^{+}$and $\mathrm{DNA}^{+}$events and combined with PElabelled markers for their further characterisation. The true endothelial origin of this population was previously confirmed by sorting this specific population and characterising it further using morphology, immunohistochemistry, multi-colour FCM and gene expression profiling (Kraan et al, 2012b). In that study, we demonstrated for this population a specific EC morphology, coexpression of vWF, CD31, CD105 and CD144, which are all considered endothelial cell markers, and additionally found that this population exhibits an EC specific gene profile.

Statistical analysis. Statistical analysis was performed using Prism software (GraphPad Software, La Jolla, CA, USA). The MannWhitney $U$-test was used to evaluate differences between ECs populations in tissue and $\mathrm{PB}$. $P$-values $<0.05$ are considered significant.

\section{RESULTS}

Immunophenotype of tissue-derived ECs. Based on the previous work of ourselves (Kraan et al, 2012b) and others (Goon et al, 2006; Dignat-George et al, 2007), viable ECs were identified by 
multiparameter flow cytometry using a combination of exclusion and inclusion markers combined with a permeant DNA-specific dye (DRAQ5) to detect nucleated cells, and a non-permeant dye (DAPI) to exclude dead cells. EC were identified by staining with two pan-endothelial antibodies (CD34 and CD146), whereas CD45 served to exclude leukocytes and non-specific binding of $\mathrm{mAb}$ on tissue cells. Using these criteria we were able to identify a small population of vital EC from tissue specimens containing normal or malignant tissue defined as $\mathrm{CD} 34^{++}, \mathrm{CD} 146^{+}, \mathrm{CD} 45^{\text {neg }}, \mathrm{DNA}^{+}$ and $\mathrm{DAPI}^{\text {neg }}$ (Figure 1). In addition, we also identified a population of viable cells with a phenotype reported to be specific for pericytes (Table 1): CD $34^{\text {neg }}, \mathrm{CD} 146^{++}, \mathrm{CD} 45^{\text {neg }}, \mathrm{DNA}^{+}$and $\mathrm{DAPI}^{\text {neg. }}$. In order to verify the nature of ECs and pericytes, we performed additional stainings with a panel of antibodies containing endothelial and pericyte-associated markers that were not used in the flow cytometric marker definition for the detection of these events. These results confirmed that the events assigned as EC and pericytes by this assay indeed represent these cells (Table 1 and Figure 2).

Comparison of antigen expression on normal vs tumour vasculature. We have studied the expression of endothelial
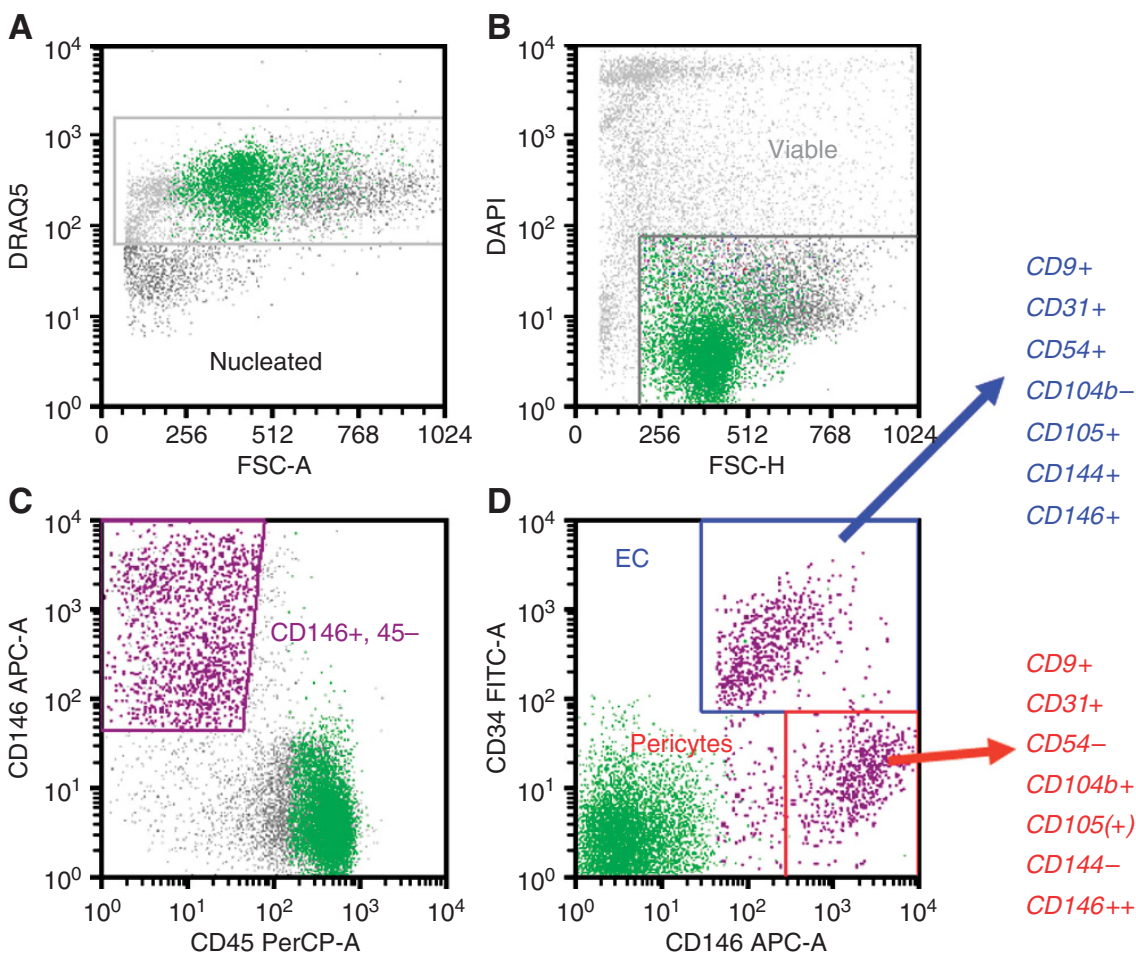

Figure 1. Flow cytometric analysis of endothelial cells and pericytes from dissected normal liver tissue. Viable nucleated cells were selected on DNA content as evidenced by the permeant dye DRAQ5 expression (A) and the absence of reactivity of the non-permeant dye DAPI (B). Endothelial cells were identified by their expression of CD146 and CD34 ${ }^{\text {bright }}$, and absence of CD45 expression. Finally, pericytes were identified by their strong expression of CD146 and dim expression of CD34 (C and D). Residual lymphocytes(green dots) in the cell isolate were used as an internal (negative) control. The seven additional markers listed on the right were evaluated using separate PE-labelled antibodies as shown in Figure 2.

Table 1. Reported expression of different endothelial and pericyte-associated antigens on isolated endothelial and pericyte populations from healthy donors by flow cytometry

\begin{tabular}{|c|c|c|c|}
\hline Marker & Endothelial Cells ${ }^{a}$ & Pericytes $^{a}$ & References \\
\hline CD9 (TSPAN29) & ++ & ++ & (Lijnen et al, 2000) \\
\hline CD31 (PECAM-1) & ++ & - & (Crisan et al, 2008; Kraan et al, 2012a) \\
\hline CD34 (Stem cell marker) & ++ & - & (Crisan et al, 2008; Zimmerlin et al, 2010; Kraan et al, 2012a) \\
\hline CD45 (pan-leucocyte) & - & - & (Crisan et al, 2008; Kraan et al, 2012a) \\
\hline CD54 (ICAM-1) & + & - & (Kraan et al, 2012a) \\
\hline CD105 (Endoglin) & + & \pm & (Rowand et al, 2007; Kraan et al, 2012a) \\
\hline CD133 (Stem cell marker) & - & - & (Kraan et al, 2012a) \\
\hline CD140b (PDGF-RB) & - & + & (Crisan et al, 2008) \\
\hline CD141 (Thrombomodulin) & + & + & (Rowand et al, 2007; Kraan et al, 2012a) \\
\hline CD144 (VE-Cadherin) & + & - & (Crisan et al, 2008; Kraan et al, 2012a) \\
\hline CD146 (MelCAM) & + & ++ & (Crisan et al, 2008; Zimmerlin et al, 2010; Kraan et al, 2012a) \\
\hline
\end{tabular}


cell-specific and associated antigens on paired cell suspensions prepared from 17 tumours and normal tissues from the same patients.

Macroscopically normal tissues were obtained from (partially) resected liver $(N=10)$, vein $(N=4)$, peritoneum $(n=2)$ and kidney $(N=1)$ tissue. These markers included thrombomodulin (CD141), VE-cadherin (CD144), MelCAM (CD146) and VEGFR-2 (CD309). In this study, we also addressed the following putative malignancy-associated antigens, based on published data (Table 2): ICAM-1 (CD54), endoglin (CD105), CD109 (a GPI-linked member of the complement superfamily), CD137 (tumour necrosis superfamily factor 90), CXCR7 (C-X-C chemokine receptor 7) and CD276 (a member of the B7 family of costimulatory molecules), all cell surface expressed proteins. Residual lymphocytes in the cell isolate were used as an internal (negative) control. No difference in antigen expression between normal and malignant ECs was found for CD54, CD109, CD137, CD141, CD144 and CXCR7. In contrast, overexpression for CD105, CD146, CD276 and CD309 was observed in tumour ECs compared with normal ECs. CD276 was most differentially expressed and chosen as a marker for further investigation (Figure 3).

CD276 expression on CEC in carcinoma patients. As CD276 was the marker with the largest difference in expression between tumour and normal ECs, it was explored whether or not a subpopulation of $\mathrm{CD}_{276^{+}} \mathrm{CEC}$ could be identified in the PB of solid cancer patients with metastatic disease.
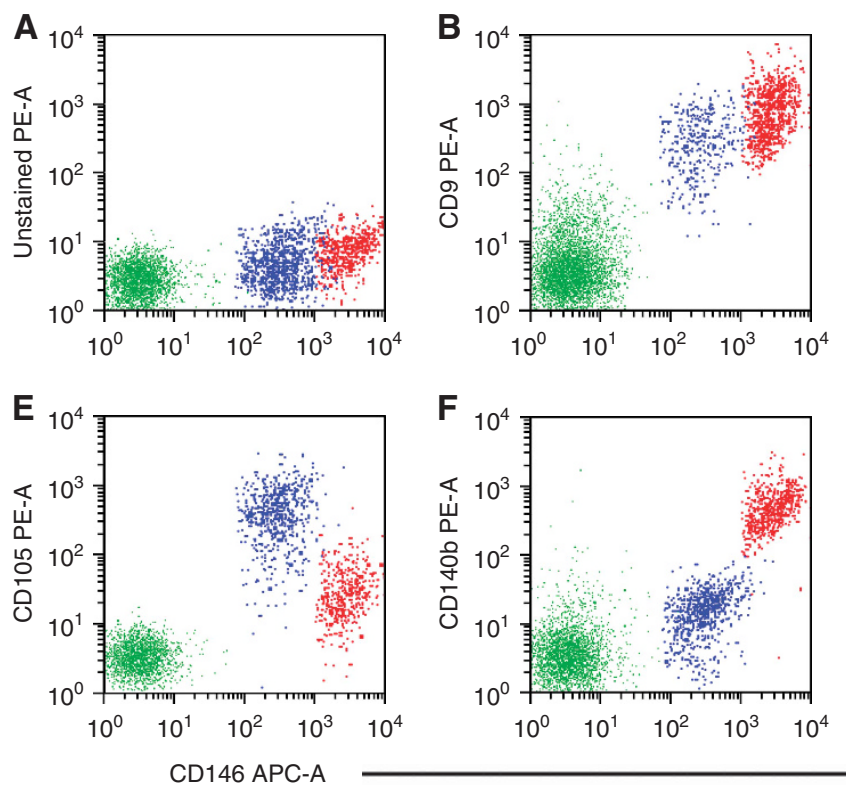

Figure 4 shows the expression of CD276 in two representative patients, one with partial expression and a low number of CD276 ${ }^{+}$ CEC (panel H) and one with a high number of $\mathrm{CD} 276^{+} \mathrm{CEC}$ (panel I). CD276 ${ }^{+}$CEC were undetectable or below 12 cells per $4 \mathrm{ml}$ in healthy donors (Figures $4 \mathrm{G}$ and 5).

Although the investigation of CD276 ${ }^{+}$CEC levels in different types of cancer other than for validation purposes is beyond the scope of this paper, Figure 5 shows that CD276 ${ }^{+}$CEC levels in healthy individuals ranged from 0 to 11 cells per $4 \mathrm{ml}(n=24$, median 3) and that the levels of these cells were significantly higher in patients with advanced CRC (ranging from 1 to 293 ( $n=15$, median $9, P<0.005)$ ), in patients with a GBM (range: 0 to 804 $(n=83$, median $10, P<0.0001))$ and patients with advanced breast cancer (range: 0 to $390(n=14$, median 13.5, $P<0.05))$. Taking all patients with malignancies together, $58 \%$ of them had more $\mathrm{CD}_{276}{ }^{+}$CEC than the upper limit of the normal range (ULN) for healthy individuals, defined as: mean $+196 \times$ s.d., which is 8 CD276 ${ }^{+}$CEC per $4 \mathrm{ml}$. When stratified for the different types of cancer, the percentage of patients with CD276 ${ }^{+}$CEC above ULN were $53 \%, 58 \%$ and $64 \%$, respectively for patients with advanced CRC, GBM and advanced breast cancer, respectively.

\section{DISCUSSION}

Recent studies suggest that tumour-derived EC possess different characteristics from normal EC, including morphologic (McDonald and Choyke, 2003), cytogenetic (Hida et al, 2004)
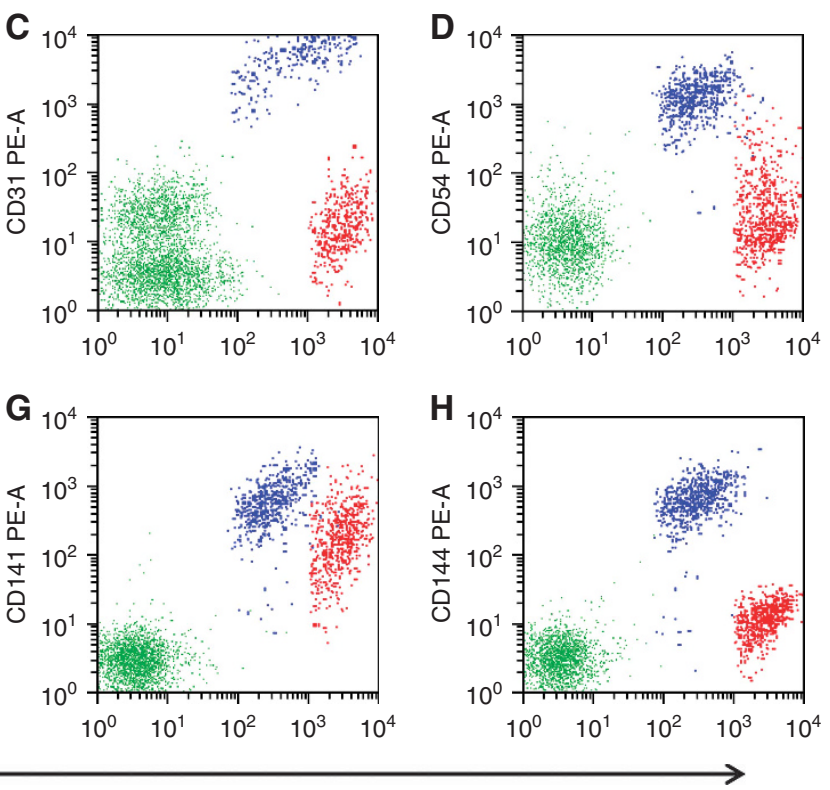

Figure 2. (A-H) Immunophenotypic characteristics of endothelial cells (blue dots) and pericytes (red dots) isolated from tissue dissections. Lymphocytes (green dots) are serving as an internal (negative) control.

Table 2. Reported tumour-associated endothelial markers (TEM)

\begin{tabular}{|c|c|c|}
\hline Marker & Cell surface expression on tumour endothelium & References \\
\hline CD54 (ICAM-1) & Downregulated in renal cell carcinoma & (Griffioen et al, 1996) \\
\hline CD105 (endoglin) & Upregulated in breast, colon, cervix, lung, prostate and brain tumours & (Duff et al, 2003; Minhajat et al, 2006) \\
\hline CD109 & Upregulated in breast, colon and lung carcinoma & (Seaman et al, 2007) \\
\hline CD137 (4-1BB) & Upregulated in colon and lung carcinoma & (Broll et al, 2001; Seaman et al, 2007) \\
\hline CXCR7 & Upregulated in renal cell carcinoma and meningioma & (Wurth et al, 2011; Maishi et al, 2012) \\
\hline CD276 (B7-H3) & Upregulated in breast, colon, lung, renal carcinoma and Glioblastoma & (Seaman et al, 2007; Lemke et al, 2012; Qin et al, 2013) \\
\hline
\end{tabular}



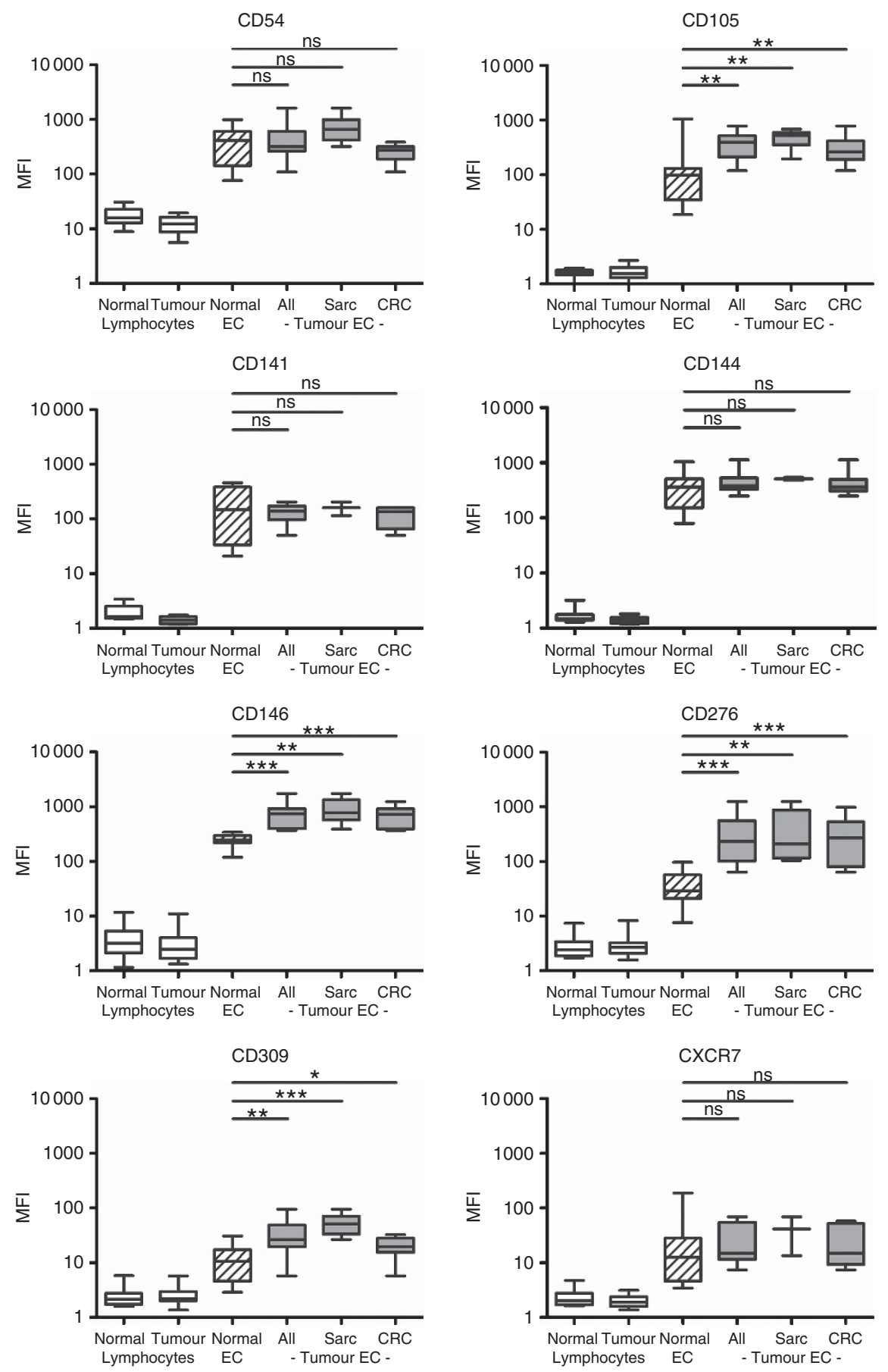

Figure 3. Antigen expression (mean fluorescence intensity) on lymphocytes (left two bars) and endothelial cells (right four bars) isolated from dissected normal and tumour tissue. Sarcoma $(N=6)$, colorectal cancer $(N=11)$ and all tumours $(N=17$; sarcoma and colorectal taken together) are separately displayed. Solid lines indicate the median value for each group. $P$-values: ${ }^{\star} P<0.05 ;{ }^{\star \star} P<0.01 ;{ }^{\star \star \star} P<0.001$.

and pathophysiologic (Hagendoorn et al, 2006) features as well as a different gene expression profile (St Croix et al, 2000).

In a previous study, we have described a flow cytometric method to enumerate ECs circulating in the $\mathrm{PB}$ and in the same study, we extensively validated the true endothelial origin of this population assigned as CEC (Kraan et al, 2012b). This method enabled us to identify markers that can be used to differentiate between CECs from n-CEC vs CEC derived from damaged t-CEC as measured in the $\mathrm{PB}$ of cancer patients. Using this flow cytometric approach, we were successful to isolate a pure endothelial cell population from normal and malignant tissues. To the best of our knowledge, this is the first time that such a method is described, which enables the isolation of EC from dissociated tissue by multiparameter flow cytometry without preenrichment and the possibility to distinguish EC from non-EC such as pericytes. We feel that this method can be further used to investigate the characteristics of ECs in more detail.

Subsequently, we studied ECs from normal and malignant tissue for their expression of cell surface markers that have been suggested in the literature as being differentially expressed. Potential TEM such as CD54, CD109, CD137 and CXCR7 did not differ in expression between ECs derived from normal and malignant tissue in a series of colorectal carcinomas and liposarcomas. In contrast, higher expression of CD105, CD146 

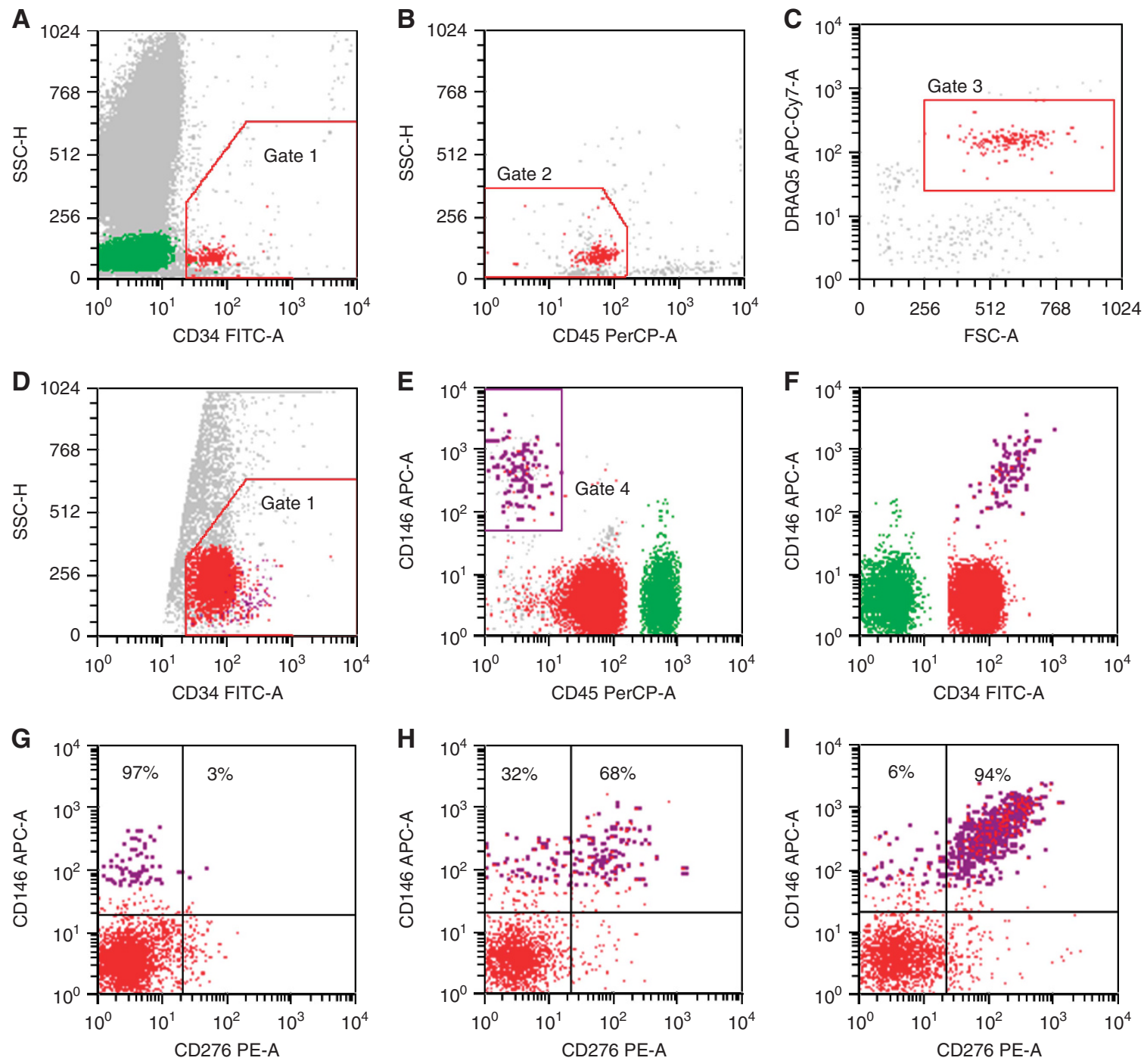

Figure 4. CD276 expression on circulating endothelial cells (CEC, purple dots). CEC are distinguished as a small population within the CD34 ${ }^{+}$ progenitor cells (red dots: $\mathrm{CD}_{4} 4^{+}, \mathrm{CD}_{4} 5^{\text {neg/dim }}, \mathrm{DNA} / \mathrm{DRAQ} 5^{+} ; \mathrm{A}-\mathrm{C}$ ). For optimal detection of the rare $\mathrm{CEC}$ population, all CD34 ${ }^{+}$cells in a total of $4 \mathrm{ml}$ blood were analysed using a threshold on CD34 (D). CEC are identified as positive for CD146 and negative for CD45 (E). E and F are overlay histograms combining the lymphocytes (internal control, including a small subset of CD146 ${ }^{+} \mathrm{T}$ lymphocytes; green dots) from the first 50000 events acquired without a CD34 threshold, and all CD34-positive events using a threshold on the remaining cells (red and violet dots). (G-I) shows the absence of CD276 expression on CEC from a healthy individual (G) vs partial (H) and high (I) expression on CEC from two representative carcinoma patients.

and CD309 was found on tumour EC compared with EC from normal tissue. These observations are in line with other reports. Overexpression of CD105 on tumour-associated EC has been reported for hepatocellular carcinoma (Xiong et al, 2009), breast, colon, lung, prostate and brain tumours (Duff et al, 2003), whereas upregulation of CD146 and CD309 has been described in many cancers including breast, prostate, melanoma and glioma (Plate et al, 1993; Ouhtit et al, 2009). In our series, the largest difference was found for CD276 with higher expression on tumour EC compared with normal tissue EC. CD276 is a member of the B7 family of immunoregulatory molecules that can be induced on $\mathrm{T}$ cells, B cells and dendritic cells by a variety of inflammatory cytokines (Chapoval et al, 2001; Steinberger et al, 2004). The ligand for CD276 has not been identified yet as well as its immunoregulatory role. $\mathrm{CD} 276$ has been suggested to have a role in the interaction between tumours and the immune system. Lemke et al, 2012 showed that natural killer cell-mediated cell lysis was proportionally suppressed as a function of CD276 expression on tumour target cells. In addition, several others have shown that expression of CD276 was associated with a relatively aggressive tumour behaviour in a range of various carcinomas (Sun et al, 2006; Roth et al, 2007; Crispen et al, 2008; Yamato et al, 2009; Zang et al, 2010; Qin et al, 2013) and GBM (Lemke et al, 2012). In line with our data, also others have shown that CD276 is differentially expressed between normal and malignant ECs. St Croix and colleagues used SAGE technology in a transcriptomic comparison of gene expression patterns of EC derived from normal resting tissue, from tumours and from regenerating liver in order to reveal differences between physiological and pathological angiogenesis (Seaman et al, 2007). Twenty-five transcripts were identified to be overexpressed in tumour $v$ s normal endothelium, including 13 that were undetectable in angiogenic endothelium of regenerating liver. Seven of this transcripts encoded known cell surface proteins, of which CD276(B7-H3) was the most differentially expressed TEM.

As CD276 was the most differentially expressed TEM, we subsequently determined the presence of CD276 ${ }^{+}$CEC in healthy controls and in three groups of patients with advanced tumours (colorectal cancer, GBM and breast cancer). 


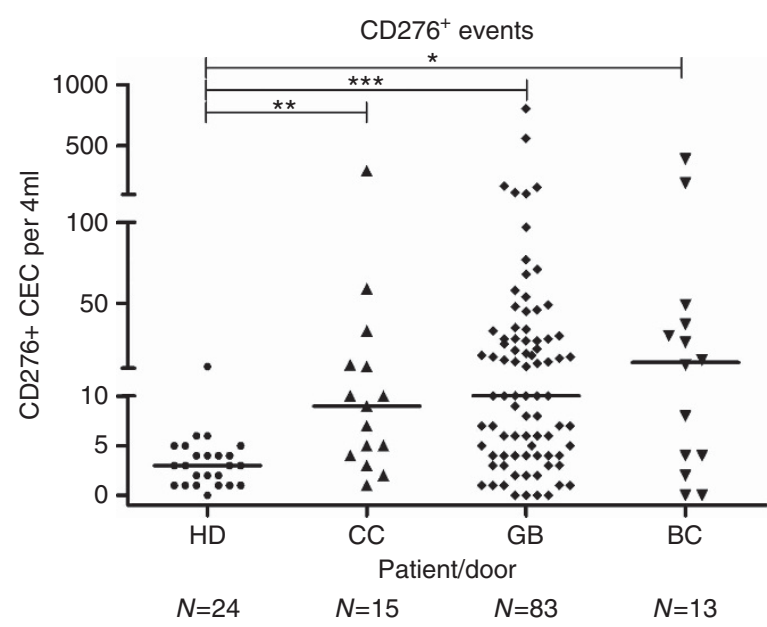

Figure 5. Absolute counts of CD276 ${ }^{+}$CEC in $4 \mathrm{ml}$ of blood from 24 healthy individuals (HD), 15 patients with advanced CRC (CC), 83 with glioblastoma (GB) and 13 with advanced breast cancer (BC). Solid lines indicate the median value for each group. Differences between $\mathrm{HD}$ and cancer patients were significant $\left({ }^{\star} P<0.05 ;{ }^{* \star} P<0.01 ;{ }^{* \star *} P<0.001\right)$.

The levels of CD276 ${ }^{+}$CEC were significantly increased in all patient groups and $58 \%$ of all patients had CD276 ${ }^{+}$CEC numbers above the ULN (53, 58 and 64\%, respectively). Although no clear differences in incidence or numbers of CD276 ${ }^{+}$CECs between these three tumour types could be identified, this study was not powered to detect such differences.

The relatively small series of this study is one of its limitations. Another limitation is that the $\mathrm{CD} 276^{+} \mathrm{CEC}$ numbers were not correlated to clinical outcome as a consequence of which the clinical relevance of this cell population remains to be defined.

In conclusion, the present study shows that CD276 can be used to discriminate ECs from malignant tissue from ECs from normal tissue. In addition, CD276 ${ }^{+}$CEC do occur in higher frequencies in patients with advanced cancer. In addition to defining potential differences between various tumour types and tumour stages, it is important to further investigate the potential clinical relevance of these cells in oncology.

To do so, further clinical studies are needed to investigate the association of $\mathrm{CD}_{276^{+}} \mathrm{CEC}$ levels at baseline with outcome, to examine the use of $\mathrm{CD} 276^{+} \mathrm{CEC}$ as a marker for response assessment by serially determining $\mathrm{CD} 276^{+}$CEC levels during treatment and to establish whether or not changes are associated with outcome to treatment as determined by conventional means, and to determine whether targets for treatment can be revealed on these cells. This will require large studies in homogenous groups of patients.

\section{REFERENCES}

Bertolini F, Mancuso P, Shaked Y, Kerbel RS (2007) Molecular and cellular biomarkers for angiogenesis in clinical oncology. Drug Discov Today 12: 806-812.

Broll K, Richter G, Pauly S, Hofstaedter F, Schwarz H (2001) CD137 expression in tumor vessel walls. High correlation with malignant tumors. Am J Clin Pathol 115: 543-549.

Carmeliet P, Jain RK (2011) Molecular mechanisms and clinical applications of angiogenesis. Nature 473: 298-307.

Chapoval AI, Ni J, Lau JS, Wilcox RA, Flies DB, Liu D, Dong H, Sica GL, Zhu G, Tamada K, Chen L (2001) B7-H3: a costimulatory molecule for T cell activation and IFN-gamma production. Nat Immunol 2: 269-274.

Crisan M, Yap S, Casteilla L, Chen CW, Corselli M, Park TS, Andriolo G, Sun B, Zheng B, Zhang L, Norotte C, Teng PN, Traas J, Schugar R, Deasy BM, Badylak S, Buhring HJ, Giacobino JP, Lazzari L, Huard J, Peault B (2008)
A perivascular origin for mesenchymal stem cells in multiple human organs. Cell Stem Cell 3: 301-313.

Crispen PL, Sheinin Y, Roth TJ, Lohse CM, Kuntz SM, Frigola X, Thompson RH, Boorjian SA, Dong H, Leibovich BC, Blute ML, Kwon ED (2008) Tumor cell and tumor vasculature expression of B7-H3 predict survival in clear cell renal cell carcinoma. Clin Cancer Res 14: 5150-5157.

Dignat-George F, Sabatier F, Blann A, Woywodt A (2007) Detection of circulating endothelial cells: CD146-based magnetic separation enrichment or flow cytometric assay? J Clin Oncol 25: e1-e2; author reply e3-5.

Duff SE, Li C, Garland JM, Kumar S (2003) CD105 is important for angiogenesis: evidence and potential applications. FASEB J 17: 984-992.

Goon PK, Boos CJ, Stonelake PS, Blann AD, Lip GY (2006) Detection and quantification of mature circulating endothelial cells using flow cytometry and immunomagnetic beads: a methodological comparison. Thromb Haemost 96: 45-52.

Griffioen AW, Damen CA, Martinotti S, Blijham GH, Groenewegen G (1996) Endothelial intercellular adhesion molecule-1 expression is suppressed in human malignancies: the role of angiogenic factors. Cancer Res 56: 1111-1117.

Hagendoorn J, Tong R, Fukumura D, Lin Q, Lobo J, Padera TP, Xu L, Kucherlapati R, Jain RK (2006) Onset of abnormal blood and lymphatic vessel function and interstitial hypertension in early stages of carcinogenesis. Cancer Res 66: 3360-3364.

Hida K, Hida Y, Amin DN, Flint AF, Panigrahy D, Morton CC, Klagsbrun M (2004) Tumor-associated endothelial cells with cytogenetic abnormalities. Cancer Res 64: 8249-8255.

Kraan J, Sleijfer S, Foekens JA, Gratama JW (2012a) Clinical value of circulating endothelial cell detection in oncology. Drug Discov Today 17: $710-717$.

Kraan J, Strijbos MH, Sieuwerts AM, Foekens JA, den Bakker MA, Verhoef C, Sleijfer S, Gratama JW (2012b) A new approach for rapid and reliable enumeration of circulating endothelial cells in patients. J Thromb Haemost 10: 931-939.

Lemke D, Pfenning PN, Sahm F, Klein AC, Kempf T, Warnken U, Schnolzer M, Tudoran R, Weller M, Platten M, Wick W (2012) Costimulatory protein $4 \mathrm{IgB} 7 \mathrm{H} 3$ drives the malignant phenotype of glioblastoma by mediating immune escape and invasiveness. Clin Cancer Res 18: 105-117.

Lijnen HR, Lupu F, Collen D, Le Naour F, Boucheix C (2000) CD9 gene deficiency does not affect smooth muscle cell migration and neointima formation after vascular injury in mice. Thromb Haemost 83: 956-961.

Maishi N, Ohga N, Hida Y, Akiyama K, Kitayama K, Osawa T, Onodera Y, Shinohara N, Nonomura K, Shindoh M, Hida K (2012) CXCR7: a novel tumor endothelial marker in renal cell carcinoma. Pathol Int 62: 309-317.

McDonald DM, Choyke PL (2003) Imaging of angiogenesis: from microscope to clinic. Nat Med 9: 713-725.

Minhajat R, Mori D, Yamasaki F, Sugita Y, Satoh T, Tokunaga O (2006) Organ-specific endoglin (CD105) expression in the angiogenesis of human cancers. Pathol Int 56: 717-723.

Nagy JA, Chang SH, Shih SC, Dvorak AM, Dvorak HF (2010) Heterogeneity of the tumor vasculature. Semin Thromb Hemost 36: 321-331.

Naumov GN, Bender E, Zurakowski D, Kang SY, Sampson D, Flynn E, Watnick RS, Straume O, Akslen LA, Folkman J, Almog N (2006) A model of human tumor dormancy: an angiogenic switch from the nonangiogenic phenotype. J Natl Cancer Inst 98: 316-325.

Ouhtit A, Gaur RL, Abd Elmageed ZY, Fernando A, Thouta R, Trappey AK, Abdraboh ME, El-Sayyad HI, Rao P, Raj MG (2009) Towards understanding the mode of action of the multifaceted cell adhesion receptor CD146. Biochim Biophys Acta 1795: 130-136.

Plate KH, Breier G, Millauer B, Ullrich A, Risau W (1993) Up-regulation of vascular endothelial growth factor and its cognate receptors in a rat glioma model of tumor angiogenesis. Cancer Res 53: 5822-5827.

Qin X, Zhang H, Ye D, Dai B, Zhu Y, Shi G (2013) B7-H3 is a new cancer-specific endothelial marker in clear cell renal cell carcinoma. Onco Targets Ther 6: 1667-1673.

Roth TJ, Sheinin Y, Lohse CM, Kuntz SM, Frigola X, Inman BA, Krambeck AE, McKenney ME, Karnes RJ, Blute ML, Cheville JC, Sebo TJ, Kwon ED (2007) B7-H3 ligand expression by prostate cancer: a novel marker of prognosis and potential target for therapy. Cancer Res 67: 7893-7900.

Rowand JL, Martin G, Doyle GV, Miller MC, Pierce MS, Connelly MC, Rao C, Terstappen LW (2007) Endothelial cells in peripheral blood of healthy subjects and patients with metastatic carcinomas. Cytometry $A$ 71: 105-113. 
Seaman S, Stevens J, Yang MY, Logsdon D, Graff-Cherry C, Croix St B (2007) Genes that distinguish physiological and pathological angiogenesis. Cancer Cell 11: 539-554.

Croix St B, Rago C, Velculescu V, Traverso G, Romans KE, Montgomery E, Lal A, Riggins GJ, Lengauer C, Vogelstein B, Kinzler KW (2000) Genes expressed in human tumor endothelium. Science 289: 1197-1202.

Steinberger P, Majdic O, Derdak SV, Pfistershammer K, Kirchberger S, Klauser C, Zlabinger G, Pickl WF, Stockl J, Knapp W (2004) Molecular characterization of human $4 \mathrm{Ig}-\mathrm{B} 7-\mathrm{H} 3$, a member of the B7 family with four Ig-like domains. J Immunol 172: 2352-2359.

Strijbos MH, Gratama JW, Kraan J, Lamers CH, den Bakker MA, Sleijfer S (2008) Circulating endothelial cells in oncology: pitfalls and promises. Br J Cancer 98: 1731-1735.

Sun Y, Wang Y, Zhao J, Gu M, Giscombe R, Lefvert AK, Wang X (2006) B7-H3 and B7-H4 expression in non-small-cell lung cancer. Lung Cancer 53: $143-151$.

Wurth R, Barbieri F, Bajetto A, Pattarozzi A, Gatti M, Porcile C, Zona G, Ravetti JL, Spaziante R, Florio T (2011) Expression of CXCR7 chemokine receptor in human meningioma cells and in intratumoral microvasculature. J Neuroimmunol 234: 115-123.
Xiong YQ, Sun HC, Zhang W, Zhu XD, Zhuang PY, Zhang JB, Wang L, Wu WZ, Qin LX, Tang ZY (2009) Human hepatocellular carcinoma tumor-derived endothelial cells manifest increased angiogenesis capability and drug resistance compared with normal endothelial cells. Clin Cancer Res 15: 4838-4846.

Yamato I, Sho M, Nomi T, Akahori T, Shimada K, Hotta K, Kanehiro H, Konishi N, Yagita H, Nakajima Y (2009) Clinical importance of B7-H3 expression in human pancreatic cancer. Br J Cancer 101: 1709-1716.

Zang X, Sullivan PS, Soslow RA, Waitz R, Reuter VE, Wilton A, Thaler HT, Arul M, Slovin SF, Wei J, Spriggs DR, Dupont J, Allison JP (2010) Tumor associated endothelial expression of $\mathrm{B} 7-\mathrm{H} 3$ predicts survival in ovarian carcinomas. Mod Pathol 23: 1104-1112.

Zimmerlin L, Donnenberg VS, Pfeifer ME, Meyer EM, Peault B, Rubin JP, Donnenberg AD (2010) Stromal vascular progenitors in adult human adipose tissue. Cytometry A 77: 22-30.

This work is published under the standard license to publish agreement. After 12 months the work will become freely available and the license terms will switch to a Creative Commons AttributionNonCommercial-Share Alike 3.0 Unported License. 